\title{
Performance Improvement for Sisal Waste Anaerobic Biodegradation by Digester Redesign and Feed Size Reduction
}

\author{
Yusufu Risasi Rajabu, Samwel Victor Manyele \\ Department of Mechanical and Industrial Engineering, College of Engineering and Technology, University of \\ Dar-es-Salaam, Dar es Salaam, Tanzania \\ Email: yusufurisasi@gmail.com, smanyele@udsm.ac.tz
}

Received 20 August 2015; accepted 17 September 2015; published 21 September 2015

Copyright (C) 2015 by authors and Scientific Research Publishing Inc.

This work is licensed under the Creative Commons Attribution International License (CC BY). http://creativecommons.org/licenses/by/4.0/

(c) (i) Open Access

\section{Abstract}

This Anaerobic Digestion of Sisal decortication residue (SDR) from sisal decorication unit at Hale biogas plant in Tanga (Tanzania) is presented. The study was done to address the challenges facing Katani limited at Hale biogas plant. This plant was built as pilot before building other biogas plants. These challenges were like high retention time of substrate which was SDR, low biogas productivity, high investment costs due to large tanks sizes and low plant availability. From the study, it was discovered that, when particle size was reduced biogas production increased, degradation of SDR also increased and no significant change in biogas composition. Increase in biogas yield of $30 \%$ and $129 \%$ were recorded for reduced SDR compared to raw size SDR digested at atmospheric condition and $40^{\circ} \mathrm{C}$ respectivelly. SDR degradation measured in TS and VS removal efficiency, showed increase in degradation of about $5 \%$ for the reduced particle size compared to raw size particle. The study concluded that SDR was good raw material for biogas production when $90 \%$ of the particles reduced to less than $2 \mathrm{~mm}$. To maximize production, digestion must be conducted at high temperature around $40^{\circ} \mathrm{C}$ with constant monitoring and control of all parameters. This will increase plant availability by increasing efficiency and life span of the pumps and stirrers.

\section{Keywords}

Anaerobic Digestion, Sisal Decortication Residue, Biogas

\section{Introduction}

Sources for renewable energy become more and more important. Among the renewable energies, biogas has the

How to cite this paper: Rajabu, Y.R. and Manyele, S.V. (2015) Performance Improvement for Sisal Waste Anaerobic Biodegradation by Digester Redesign and Feed Size Reduction. Engineering, 7, 553-566.

http://dx.doi.org/10.4236/eng.2015.79051 
advantage that it is not a fluctuating source. Biogas can be gained in an anaerobic digestion process from different organic substances, e.g. from energy crops, agricultural waste or municipal organic waste [1]. The biomethane from sisal fibre waste, a waste product from sisal industry, especially in the small-scale or local industry, is of great interest as a renewable energy carrier that could be used for cooking and/or power gene- ration [2]. The sisal industry traditionally utilizes only $5 \%$ of the total weight of the leaf in sisal fibre production, and the remaining 95\% is being regarded as waste [3]. Fifty-two (52) sisal factories in Tanzania produce about 444,000 tons of waste pulp and 148,000 tons of waste fibre annually, which is often dumped on land or in nearby rivers where it is degraded by microorganisms under uncontrolled conditions [4].

The main environmental impacts of sisal factories are related to water pollution and greenhouse gas (GHG) emissions by the sisal waste and by-products. Both the solid waste at the disposal sites and the wastewater in the lagoons increase emissions of methane gas to the atmosphere, generated after the decay of the degradable organic carbon (DOC) in the waste. Sisal waste, however, constitutes a major potential source of clean energy if digested anaerobically under controlled conditions to generate biogas [3]. Methane has a global warming potential that is 21 - 56 times higher than that of carbon dioxide, and is estimated to contribute to $18 \%-21 \%$ of the overall global warming [5].

Katani limited is facing the problem of Sisal Decortications Residue (SDR) and decides to utilize them to produce biogas. The pilot plant was built at Hale to digest SDR to produce biogas. However, performance of the plant has been experiencing challenges like high retention time that reduce productivity and lead to high investment cost due to large tank sizes required. These challenges made Katani limited hesitate to build other biogas plants. To overcome the mentioned challenges, one of the suggested methods is to improve kinetics of biochemical reactions by mechanical pre-treatment of SDR in order to reduce the size of particles. This can speed up digestibility process of SDR, reduce digester retention time, and thus increase biogas production, reduce sizes of digesters and other tanks for space and cost-saving purposes.

\section{Literature Review}

\subsection{Overview of Anaerobic Digestion}

Anaerobic digestion is the use of biological processes, in the absence of oxygen, for the breakdown of organic matter and the stabilization of these materials, by conversion to methane and carbon dioxide gases and a nearly stable residue. Anaerobic digestion process is gaining wider acceptance in the present scenario due to production of biogas, which can be further used for meeting a part of energy demand. Energy has a major economic and political role as an important energy resource traded worldwide. Biomethanation technology may be perceived as potential alternative which does not only provides renewable source of energy but also utilizes recycling potential of degradable organic portion of waste material.

In an anaerobic digester, four processes occur simultaneously. When the anaerobic digester performs properly, the conversion of the intermediate products (i.e., the products of the first three steps) is virtually complete, so that the concentrations of these are low at any time. In the hydrolysis process, macro molecules like proteins, polysaccharides and fats are converted into molecules with a smaller atomic mass that are soluble in water: peptides, saccharides and fatty acids. The hydrolysis is a solubilisation process which is carried out by exo-enzymes excreted by fermentative bacteria. Hydrolysis is a relatively slow process and it generally limits the rate of the overall anaerobic digestion process. The second step of the anaerobic digestion process is acidogenesis or acidification, a process that results in the conversion of the hydrolysed products into simple molecules with a low molecular weight, like volatile fatty acids (e.g., acetic-, propionic- and butyric acid), alcohols, aldehydes and gases like $\mathrm{CO}_{2}, \mathrm{H}_{2}$ and $\mathrm{NH}_{3}$. In the third step, acetogenesis, the products of the acidification are converted into acetic acids, hydrogen, and carbon dioxide by acetogenic bacteria. The first three steps of anaerobic digestion are often grouped together as acid fermentation. It is important to note that in the acid fermentation, no organic material is removed from the liquid phase: it is transformed into a form suitable as substrate for the subsequent process of methanogenesis. In the final step of the anaerobic digestion process, the products of the acid fermentation (mainly acetic acid) are converted into $\mathrm{CO}_{2}$ and $\mathrm{CH}_{4}$. Only then will organic material be removed, as the produced methane gas will largely desorb from the liquid phase. In each of the four sequential steps, the catabolic reactions described above develop together with anabolic activity. The free energy released in the reactions is partially used for synthesis of the anaerobic bacterial populations [6]. 


\subsection{Anaerobic Digestion Process Parameters}

The operating parameters of the digester must be controlled so as to enhance the microbial activity and thus increase the anaerobic degradation efficiency of the system. The production of biogas is factored by many operational parameters. Some parameters that affect the production of biogas include temperature, $\mathrm{pH}$, pre- treatment, particle size, mixing, rate of organic loading, retention time, concentration of micro-organisms, type of substrate, etc. Any rapid change in these parameters can adversely affect the production of biogas [7] [8].

Anaerobic digestion systems are limited by two major steps depending on the nature of the substrates. Hydrolysis is often limited if the substrate is complex organic solids while in the digestion of soluble organic matter, the rate limiting step has been identified as methanogenesis. Since a major drawback in a bioreactor based on anaerobic digestion of soluble substrate is the slow growth rate of methanogens, the desirable degree of organic matter degradation is achieved after a long residence time in the anaerobic reactor [9].

Several methods to solubilize or hydrolyze sludge cells prior to anaerobic digestion have been investigated. Sonication can, for example, disintegrate sludge cells for $70 \%-100 \%$ but consumes $200 \mathrm{MJ} / \mathrm{kg}$ total dry solids (TDS) [10]. Chemical and thermochemical pre-treatments, based on strong acidic or basic conditions in combination with high temperatures and pressures, have been shown to be efficient in enhancing sludge digestion [11] [12]. Several authors found a doubling of the methane production after a thermochemical pre-treatment at $180^{\circ} \mathrm{C}$. However, the aggressive reaction conditions often impose special material requirements. Mechanical pre-treatment was shown to be very effective in solubilizing microbial cells but turned out to be rather complicated and expensive [10] [13].

The sizes of feedstock particles have an influence on the gas production though it is not as important parameter as $\mathrm{pH}$ and temperature of the digester content. If the particle sizes are too large, the digester might be clogged and also, the digestion of the particles will be difficult for microorganisms. On the other hand, smaller particles would provide large surface area for absorbing the microorganisms and enzymes. This will lead to increased microbial activity and hence increased gas production [7].

Sharma et al. (1988) [14] studied the effect of particle sizes on biogas production using particles of 0.088 , $0.40,1.0,6.0$ and $30.0 \mathrm{~mm}$. They found out that maximum quantity of biogas was produced from particles with smaller size $(0.088 \mathrm{~mm}$ and $0.40 \mathrm{~mm})$. However, succulent materials such as leaves with larger sizes could be used though materials such as straw and other larger particles would decrease the production of biogas. In a nut shell, the results suggested that a physical treatment such as grinding could significantly reduce the volume of the digester without decreasing the biogas production [15].

\section{Methods and Equipment}

\subsection{Substrate and Inoculum}

The sisal decortication residue (SDR) used in the experiment was collected from sisal processing plant at Hale, Tanzania. The SDR was divided into two groups, one without pre-treatment and other reduced in size by kitchen blender and then both samples were distributed on clean pieces of cloth for two days at room temperature $\left(28^{\circ} \mathrm{C}\right.$ $32^{\circ} \mathrm{C}$ ). Then samples were measured for moisture content and particle size analysis using sieve analysis. Moisture content and particle size distribution of the samples are shown in Table 1.

The sisal waste sludge (SWS) was used as inoculum since it has been found to be suitable inoculum for digester start-up [16]. The SWS was collected from digester tank at Hale biogas plant.

\subsection{Experimental Design}

\subsubsection{Laboratory Scale Digesters}

The treated SDR was digested in anaerobic laboratory batch digesters. During this experiment, untreated SDR and SDR which had been reduced in particle size were compared. To examine the effect of size reduction pretreatment on the subsequent performance of batch anaerobic digestion of SDR, the test was carried out with two different particle sizes as shown in Table 1. Each digester contained pre-treated or untreated SDR as a substrate and SWS as inoculum. The amounts of waste and inoculum were $60 \mathrm{~g}$ and $950 \mathrm{ml}$, respectively.

The experimental set-up consisted of 6 tests experiments. Two groups of experiments were conducted; one group operated at atmospheric condition $30^{\circ} \mathrm{C} \pm 2^{\circ} \mathrm{C}$ and another group at $40^{\circ} \mathrm{C}$. Each group consist of three sets of experiments; raw size SDR, reduced size SDR and inoculum as a control. Each set was made up of laboratory 
Table 1. Moisture content and particle size distribution of the sisal decortication residue.

\begin{tabular}{|c|c|c|c|c|}
\hline & \multicolumn{2}{|c|}{ Reduced size } & \multicolumn{2}{|c|}{ Raw size } \\
\hline Moisture (\%) & \multicolumn{2}{|c|}{84.47} & \multicolumn{2}{|c|}{86.79} \\
\hline Sieve size & \multicolumn{2}{|c|}{ Retained weight } & \multicolumn{2}{|c|}{ Retained weight } \\
\hline $\mathrm{mm}$ & g & $\%$ & g & $\%$ \\
\hline 4.0 & 0.6 & 1.0 & 6.5 & 11.5 \\
\hline 2.8 & 1.3 & 2.3 & 8.8 & 15.6 \\
\hline 2.0 & 2.8 & 4.9 & 15.4 & 27.4 \\
\hline 1.0 & 26.9 & 46.8 & 21.0 & 37.3 \\
\hline Remaining & 25.9 & 45.0 & 4.6 & 8.2 \\
\hline Total & 57.5 & 100 & 56.3 & 100 \\
\hline
\end{tabular}

digester with 1litre working volume, two conical flask and connecting tubes. One conical flask was connected with both laboratory digester and other conical flask. Digester was filled with substrate where by anaerobic digestion was taking place, one flask connecting both digester and another flask was filled with water, and another flask was empty as shown in Figure 1. Biogas was produced in the digesters and transported by the tubes to the flask containing water. The incoming biogas in the connecting flask pressurised water to the empty flask through the tubes. Biogas volume was obtained by measuring displaced water volume and biogas samples from connecting flasks were taken using syringe for analysis.

\subsubsection{Pilot Scale Digesters}

Two batch anaerobic digesters were used, one with capacity of 927 litres and another with 1675 litres volume for substrate. These digesters were connected to the floating drum gas holder for gas storage and calibrated to measure gas volume. Digesters were equipped with sampling points to take samples, hand driven mechanical stirrer and metallic cover to stop biogas from escaping. Also in floating drum there were gas sampling points. Digesters were filled with substrate materials and floating drum with water. Biogas produced in the digesters creates enough pressure for it to be transported to the floating drum gas holder by displacing the water. Figure 2 shows the photograph of one of the pilot plant anaerobic digester.

Because one of the objectives was to compare between experimental process and Hale biogas plant process, 1625 litres anaerobic digester was redesigned to incorporate heat exchanger for it to be operated at elevated temperature.

One of the pilot scale digester (1675 litres) was redesigned to meet the following objectives; to be able to operate at elevated temperature like higher mesophilic temperature and thermophilic temperature and to stabi- lize the process in order to be independent of the atmospheric condition [17].

Redesign of the pilot plant made possible to mimic operating condition of the Hale biogas plant and stabilize the process. As a result, microorganisms in the digester are not affected by temperature fluctuation caused by ambient temperature changes.

1) Process Description

SDR from decorticator is weighed to know its weight before feeding into the anaerobic digester through influent inlet. SDR is left to digest for required retention time. After digestion, digester materials are removed from the digester through effluent outlet as fertilizer. Temperature in the digester is controlled by heat exchanger. While SDR digestion is taking place biogas is produced in the digester. The gas produced pass through gas pipe to floating drum gas holder.

2) Illustration of the Digester before and after Redesign

Before redesign of the digester there was no heat exchanger, effluent outlet was short and the stirrers were long. In this digester it is not possible to either control temperature or operate digester at higher temperature. Temperature was changing with respect to environmental condition. During the day the temperature rises and falls during the night. Figure 3 shows the cross-section of the digester before redesign.

During redesign, a heat exchanger was added in the digester, while the effluent outlet was extended and the 


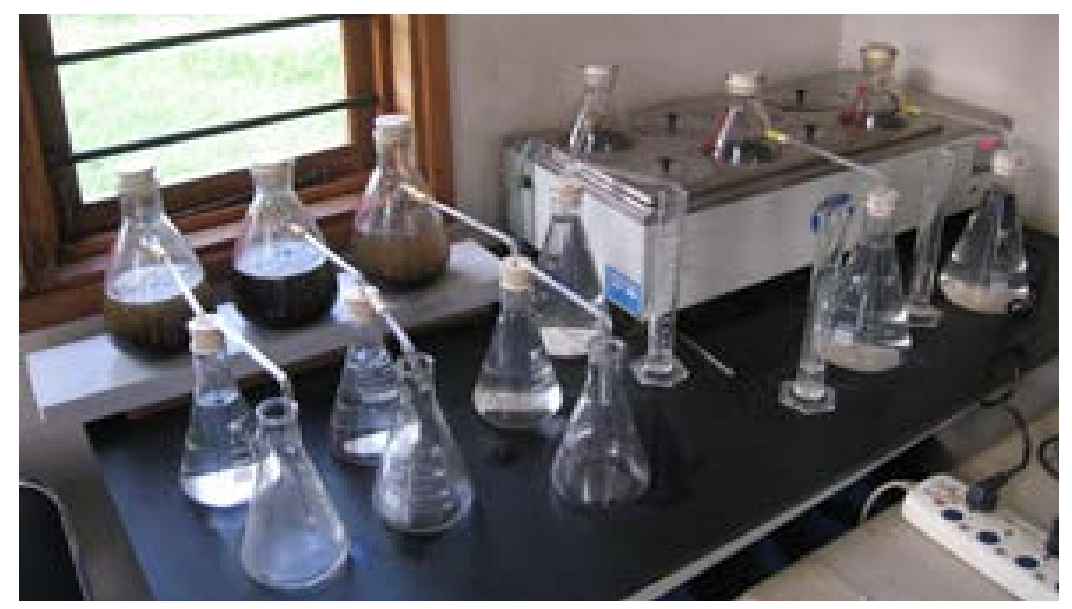

Figure 1. Setup of laboratory scale digesters.

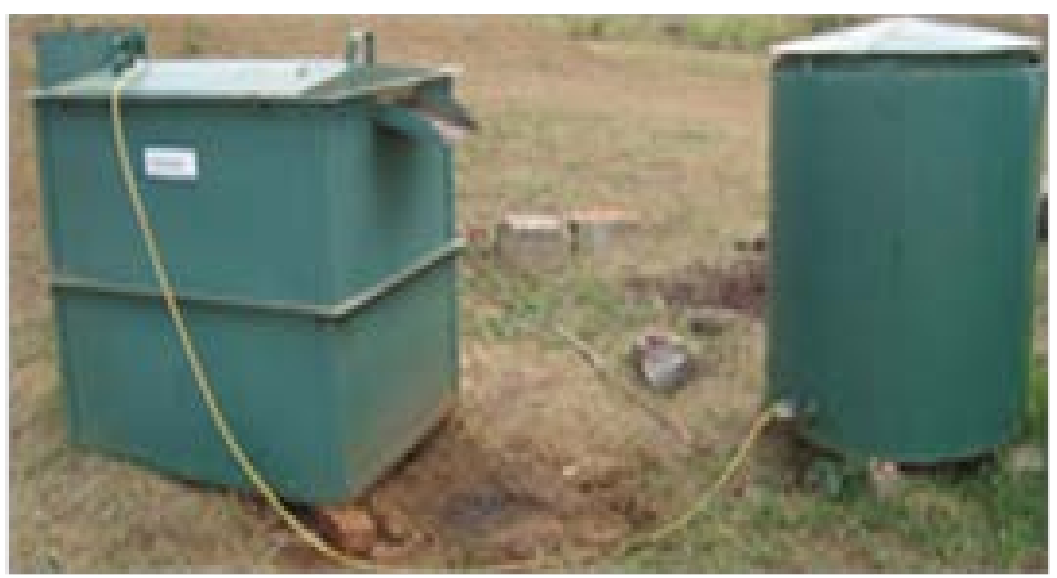

Figure 2. Pilot scale anaerobic digester.

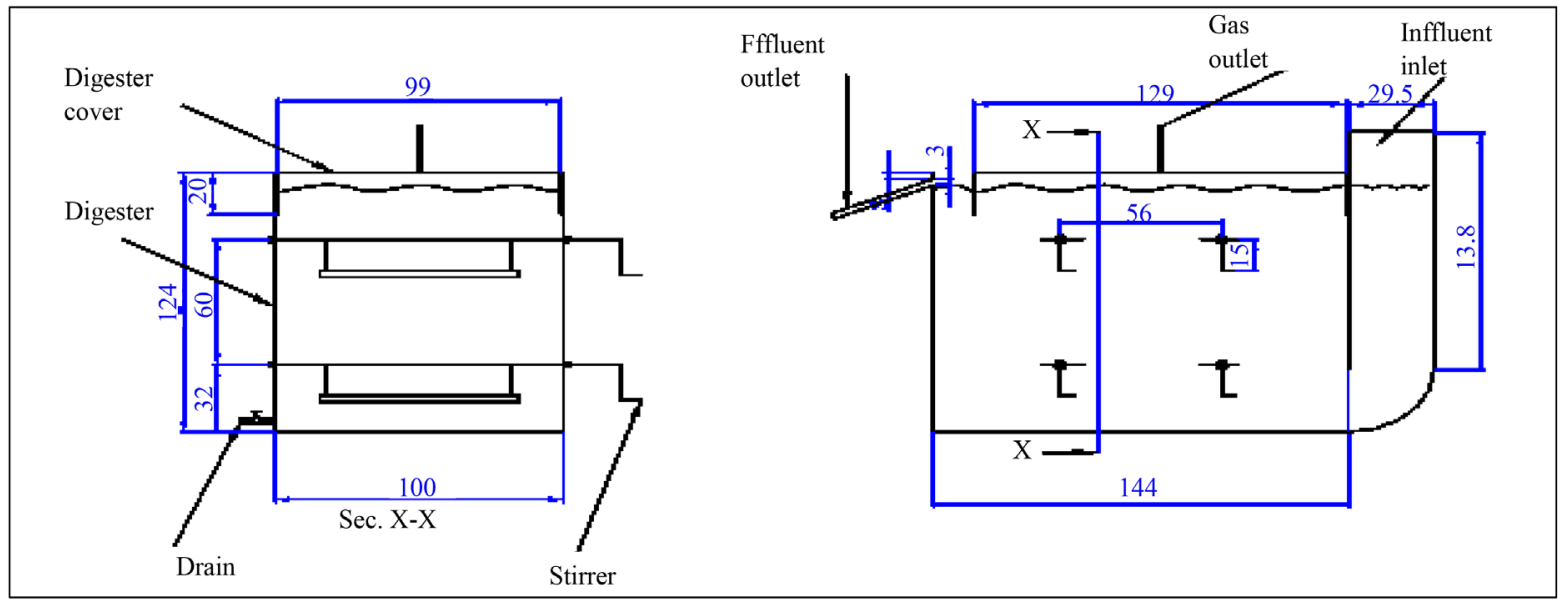

Figure 3. Cross section of the digester before redesign.

stirrers were reduced to allow passage of heat exchanger pipes. These features allow digester to be operated at high temperature and can be controlled by installation of thermostat. Also, the effluent outlet was extended to stop effluent material from dropping onto the hot water tank. Figure 4 shows the cross-section area of the digester after redesign. 


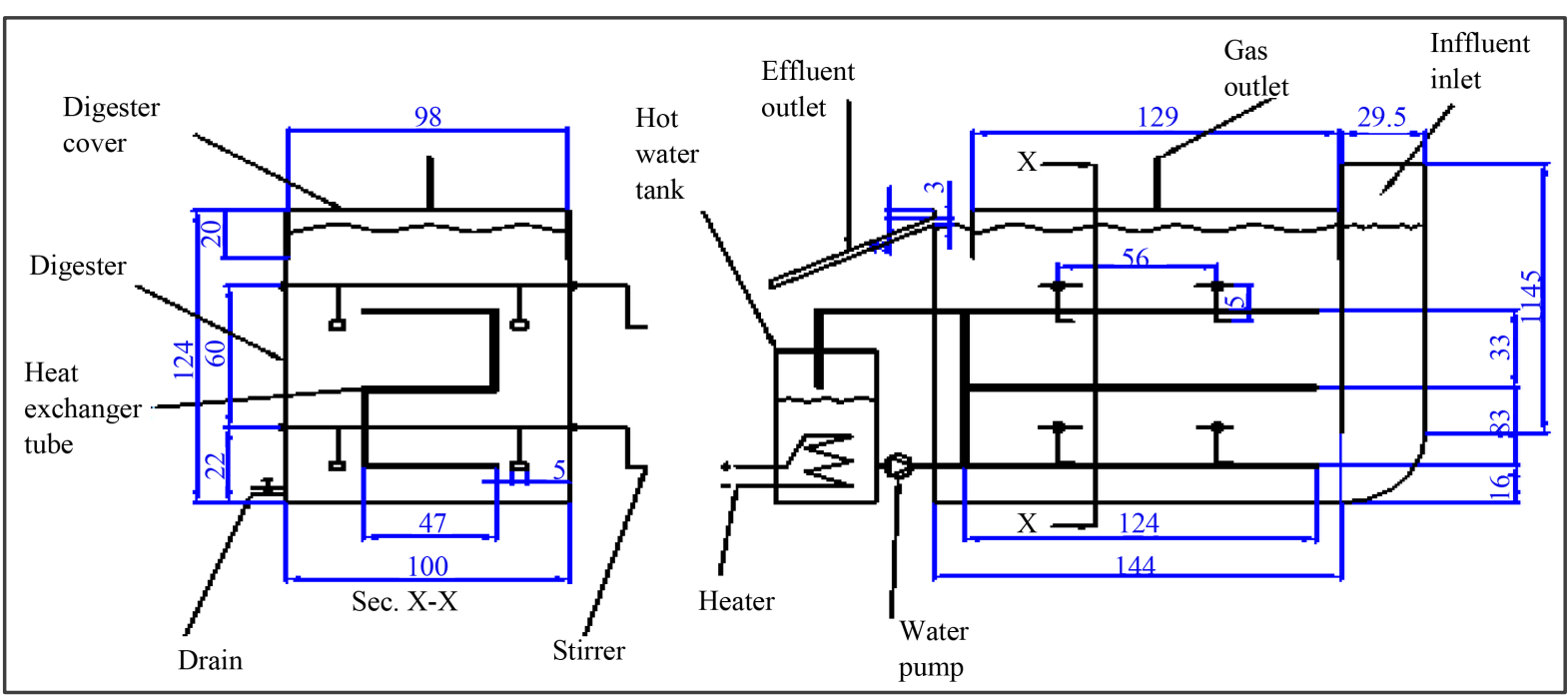

Figure 4. Cross section of the digester after redesign.

\subsection{Analytical Methods}

All sets of digestions runs were left to continue until no significant gas production were observed. Terminations were determined by biogas production trend of the digesters. The biogas volume and composition were measured and analysed daily. The gas composition was measured by Biogas Component Express Analyser. In this method, $\mathrm{CH}_{4}, \mathrm{CO}_{2}, \mathrm{H}_{2} \mathrm{~S}$ and $\mathrm{O}_{2}$ were determined. Biogas composition determination was done prior to measurement of biogas volume. Biogas yield was calculated by subtracting the amount of biogas produced by the control from the biogas production of each substrate and dividing the difference by the mass of volatile solids in the substrate fed to the digester. The process was controlled by monitoring $\mathrm{pH}$, temperature and Volatile fatty acids (VFA) for PSD while for LSD only pH and temperature were controlled. It was not possible to measure VFA in LSD because of large sample required. The digester contents were analysed for total solids (TS), volatile solids (VS) and chemical oxygen demand (COD) before and after digestion.

Total Solids (TS), volatile solids (VS) and chemical oxygen demand (COD) were determined according to standard methods [18]. VFA were determined by titrimetric method also known as Kapp method [19]. The pH was measured by $\mathrm{pH}$ meter. Substrate temperature was measured by liquid in glass thermometer.

\section{Results and Discussion}

\subsection{Effect of Particle Size on Biodegradability}

Particle sizes have significant effect on the degradability of SDR. Smaller particles provide large surface area required by the micro-organisms, resulting in increased microbial activity; thus, the anaerobic biodegradability is increased. Biodegradability of SDR was analysed in terms of TS and VS removal efficiencies and COD of the effluent. Values of TS and VS were measured before and after digestion and biodegradability values were calculated in terms of their removal efficiency. Figure 5 to Figure 6 describe biodegradability of SDR at different conditions using TS, VS and COD in LSD.

Figure 5 shows that the maximum TS removal efficiencies were $54.15 \%$ and $52.51 \%$ in reduced sizes digester operated at temperature of $40^{\circ} \mathrm{C}$ and atmospheric temperature respectively while that of unblended digester were $50.87 \%$ and $49.23 \%$ for heated and atmospheric conditions, respectively. Minimum TS removal efficiencies were $46.31 \%$ and $44.07 \%$ in inoculum digester operated at temperature of $40^{\circ} \mathrm{C}$ and atmospheric temperature respectively.

Figure 6 shows that the maximum VS removal efficiencies were $65.45 \%$ and $63.4 \%$ in reduced sizes digester operated at a temperature of $40^{\circ} \mathrm{C}$ and atmospheric temperature respectively while that of unblended digester were $60.6 \%$ and $59.3 \%$ for heated and atmospheric conditions respectively. The minimum VS removal efficiencies were $52.0 \%$ and $46.3 \%$ in inoculum digester operated at ambient temperature and $40^{\circ} \mathrm{C}$ respectively. 


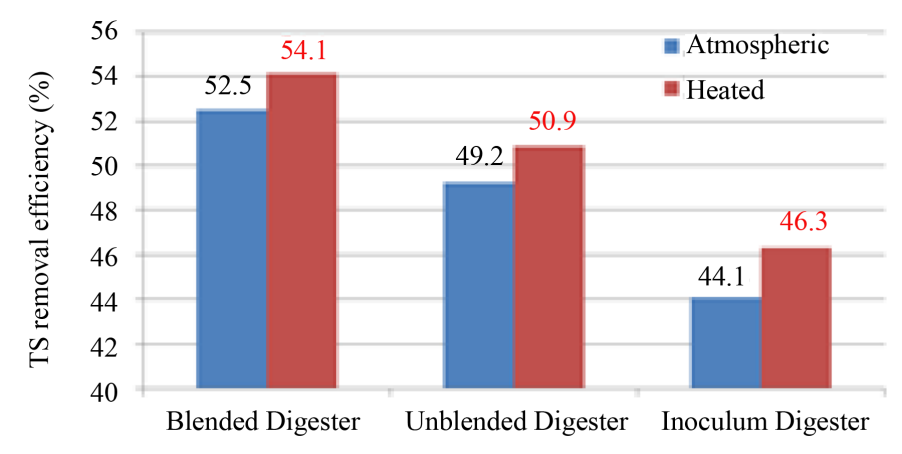

Figure 5. Comparison of total Solids removal efficiency for laboratory scale digesters.

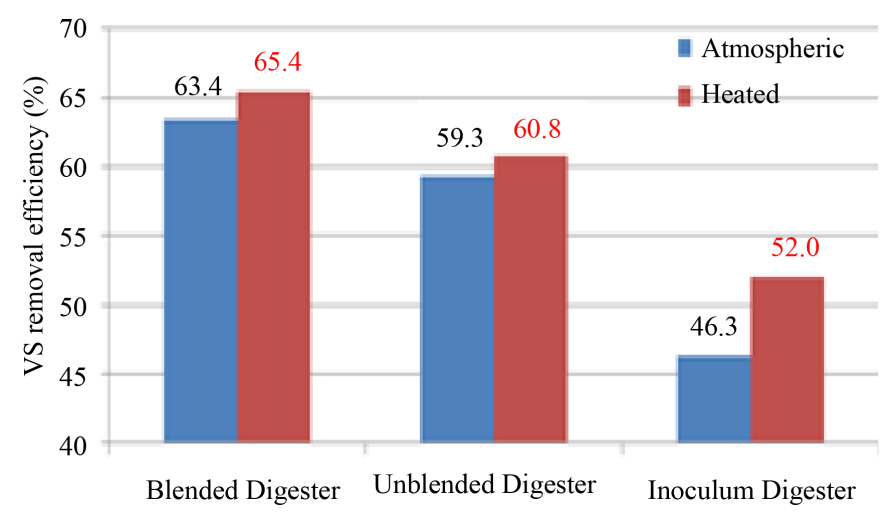

Figure 6. Comparison of volatile solids removal efficiency for laboratory scale digesters.

Figure 7 shows that the maximum COD was $10.7 \mathrm{~g} \mathrm{O}_{2} / \mathrm{dm}^{3}$ for unblended digester operated at ambient condition and minimum was $1.9 \mathrm{~g} \mathrm{O}_{2} / \mathrm{dm}^{3}$ for heated inoculum digester. COD of the other digesters are $9.8 \mathrm{~g}$ $\mathrm{O}_{2} / \mathrm{dm}^{3}$ for heated unblended digester, $8.8 \mathrm{~g} \mathrm{O}_{2} / \mathrm{dm}^{3}$ for, atmospheric blended digester, $6.6 \mathrm{~g} \mathrm{O}_{2} / \mathrm{dm}^{3}$ for heated blended digester and $2.3 \mathrm{~g} \mathrm{O}_{2} / \mathrm{dm}^{3}$ for atmospheric inoculum digester.

Similar results have been reported by other researchers. Total fibre degradation of sisal fibre waste increased from $31 \%$ to $70 \%$ for the $2 \mathrm{~mm}$ fibre compared to untreated fibres [4]. Also, $67 \%$ and $63 \%$ total fibre degradation were observed with $2 \mathrm{~mm}$ sieve mesh size of bagasse and maize bran, respectively, in batch cultures [20]. These results mean that biodegradability of the SDR increases with the decrease in size of the particles, and also increases with rise in temperature. Thus, by combining the effect of temperature rise and size reduction of the SDR maximizes the biodegradability effect.

\subsection{Effect of Particle Size on Biogas Yield Potential}

Biogas yield potential is the ability of the substrate material to produce biogas. It is very important to know the relation of any parameter with yield potential to decide whether is economically viable to change that parameter in the production process or not.

\subsubsection{Effect of Particle Size on Biogas Yield Potential on Laboratory Scale Digester}

In the LSD, biogas yield increased to $0.386 \mathrm{~m}^{3} / \mathrm{kg}$ VS when SDR was reduced in size and digested at $40^{\circ} \mathrm{C}$. This is $146 \%$ increase compared with $0.157 \mathrm{~m}^{3} / \mathrm{kg}$ VS when raw SDR was used and digested at atmospheric condition. There are also increases in reduced size SDR operated at $40^{\circ} \mathrm{C}$ (heated) and raw size SDR operated at atmospheric condition to $0.205 \mathrm{~m}^{3} / \mathrm{kg}$ VS and $0.168 \mathrm{~m}^{3} / \mathrm{kg}$ VS. These are $31 \%$ and $7 \%$ increase compared with raw size SDR digested at atmospheric condition as shown in Figure 8.

The large increase has been observed when two factors are combined, which are temperature and particle size. 


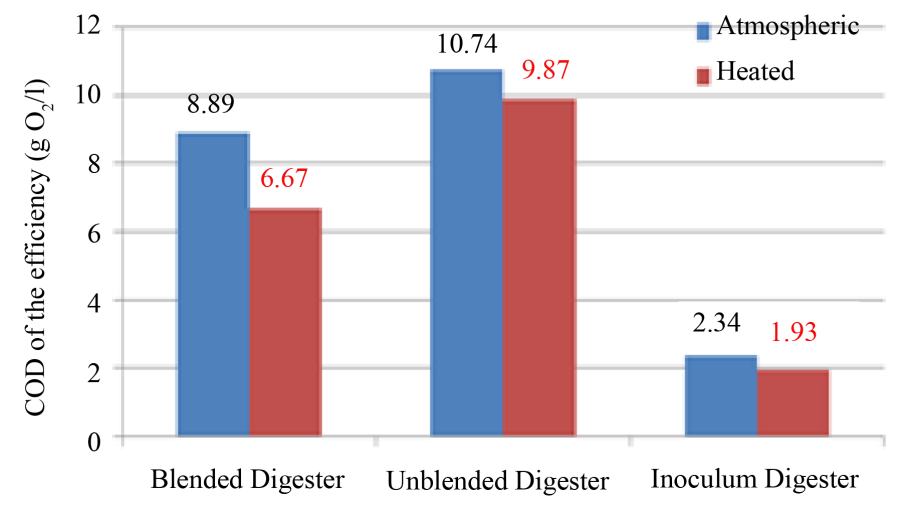

Figure 7. Comparison of Carbon Oxygen DEMAND for laboratory digesters.

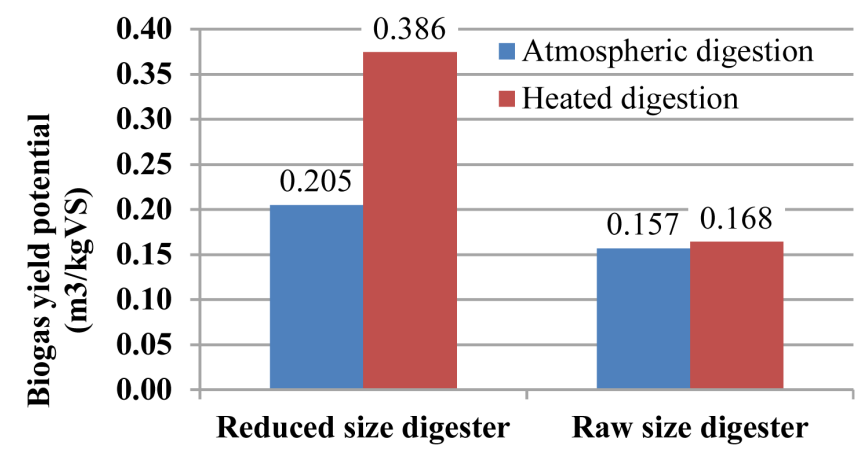

Figure 8. Biogas yield potential for SDR under different conditions.

There is $130 \%$ increase when SDR digested at same temperature of $40^{\circ} \mathrm{C}$ under reduced size and raw size. On the other hand, $88 \%$ increase has been observed when digested at different temperatures (i.e. atmospheric and $40^{\circ} \mathrm{C}$ ) of reduced size SDR (Figure 8).

The cumulative biogas volume (CBV) of SDR show that highest biogas volume collected within 14 days was from reduced size SDR digested at $40^{\circ} \mathrm{C}$ (heated) which was $3552 \mathrm{~cm}^{3}$, lead the other three by difference of more than $1500 \mathrm{~cm}^{3}$. The CBV of reduced size SDR digested at atmospheric condition was $1886 \mathrm{~cm}^{3}$ which was the second. The third and fourth were raw size SDR digested at $40^{\circ} \mathrm{C}$ with CBV of $1548 \mathrm{~cm}^{3}$ and raw size SDR digested at atmospheric condition respectively as shown in Figure 9.

Variation of heated to atmospheric operated digesters biogas volume ratio $(B V R=Y)$ with time showed that there was small change in biogas production for raw size digested SDR compared to reduced size SDR as shown in Figure 10. The ratio increased abruptly on day 9 for both reduced size and raw size. For reduced size SDR the ratio reached highest value which was 23 on $11^{\text {th }}$ day, this means increase in production rate of heated digester 23 times more compared to the one operated at atmospheric condition. For raw size SDR the ratio reached highest value which was 4 on $10^{\text {th }}$ day.

Similar results have been reported by other investigators. Methane yield increased by $23 \%$ when fibres were cut to $2 \mathrm{~mm}$ size and was $0.22 \mathrm{~m}^{3} \mathrm{CH}_{4} / \mathrm{kg}$ VS compared to $0.18 \mathrm{~m}^{3} \mathrm{CH}_{4} / \mathrm{kg}$ VS for untreated fibres [4]. As reported also by Hills and Nikano [21], working on tomato waste chopped to particle sizes in the range $1.3-20$ $\mathrm{mm}$, biogas yield increase was inversely proportional to the average particle diameter. Similarly Angelidaki and Ahring [22] reported a potential increase in methane yield of $16 \%$ for macerated manure biofilters with particle sizes between 1 and $2 \mathrm{~mm}$, as compared to the fibres of $5 \mathrm{~mm}$ particle size. This means that particle size reduction and temperature rise increases the amount of biogas produced.

\subsubsection{Effect of Particle Sizes on Biogas Yield Potential on Pilot Scale Digester (PSD)}

For the pilot scale digesters, two experiments of raw sized SDR were conducted, one at elevated temperature 


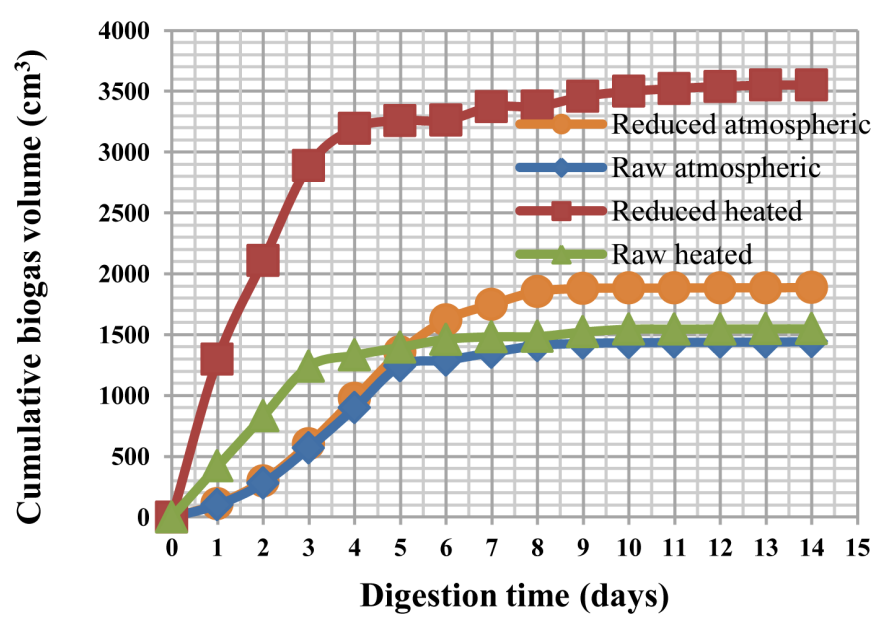

Figure 9. Cumulative biogas volume of different digestion conditions with time.

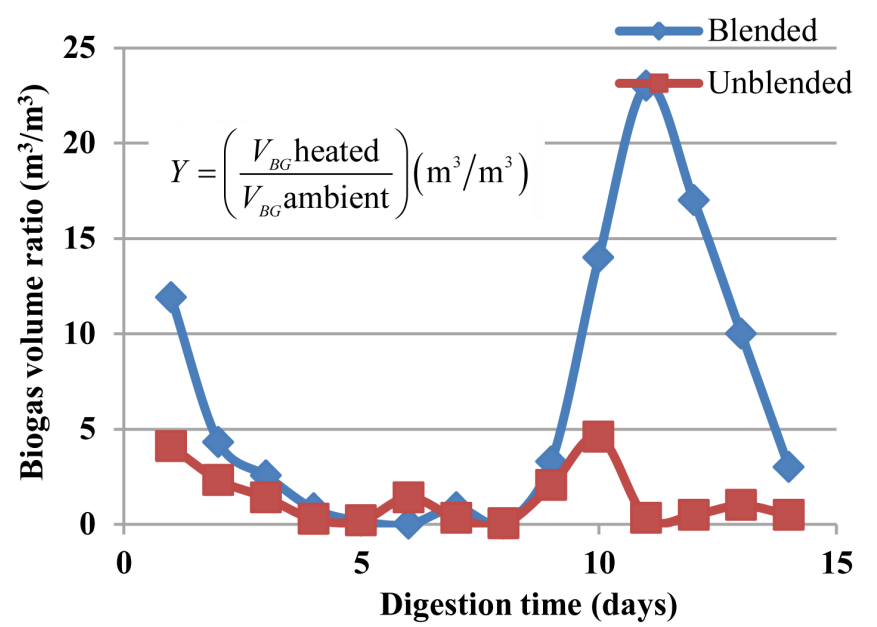

Figure 10. Variation of heated to atmospheric biogas volume ratio with time.

around $40^{\circ} \mathrm{C}$ and another at atmospheric condition. All these experiments were operated in semi continuous mode. For the reduced size experiments, blender could not have capacity to reduce size of SDR enough for pilot plant. Not only that but also removing remaining fibres of that capacity in the SDR was tedious work. Figure 11 shows biogas production per VS from pilot scale digesters operated in semi continuous mode.

The BVR of heated digester over that operated at atmospheric condition showed that in the first 6 days BVR was between 0.5 and 1.2 . In the $6^{\text {th }}$ day BVR increased abruptly until $9^{\text {th }}$ day where it reached maximum of 2.1 as shown in Figure 12.

\subsection{Analysis of Kinetics of Biodegradation Reaction ( $s$ )}

Kinetics is the study of the speed with at which a biochemical reaction occurs and the factors that affect this speed. The speed of a bio-reaction is the rate at which the concentrations of reactants and products change. This information is especially useful for determining how a reaction occurs.

In this study, substrate biodegradability was assessed by developing a mathematical model that was based on the first order kinetics. According to Linke [23], the transformation of biodegradable solids into biogas was correlated as shown in Figure 13.

The transformation can further be described by Equations (1)-(7) for a batch reactor system. 


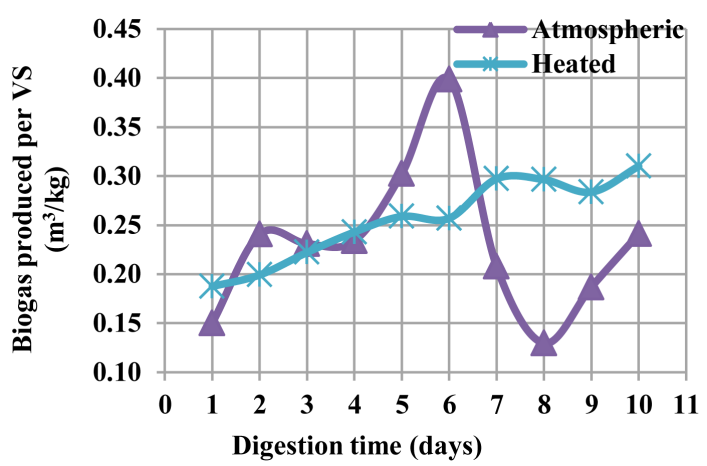

Figure 11. Biogas production per volatile solids over time for pilot scale digesters.

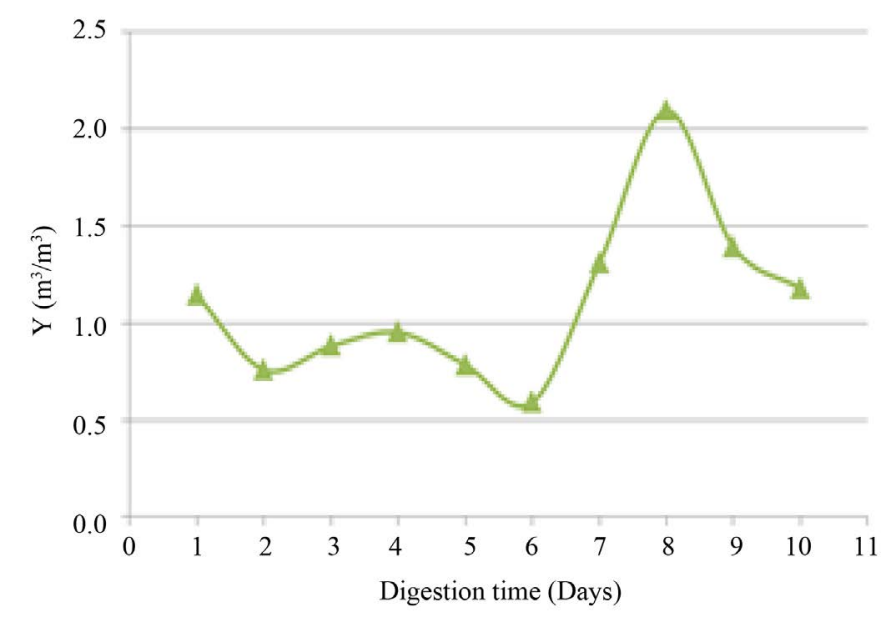

Figure 12. Variation of heated to atmospheric biogas volume ratio with time.

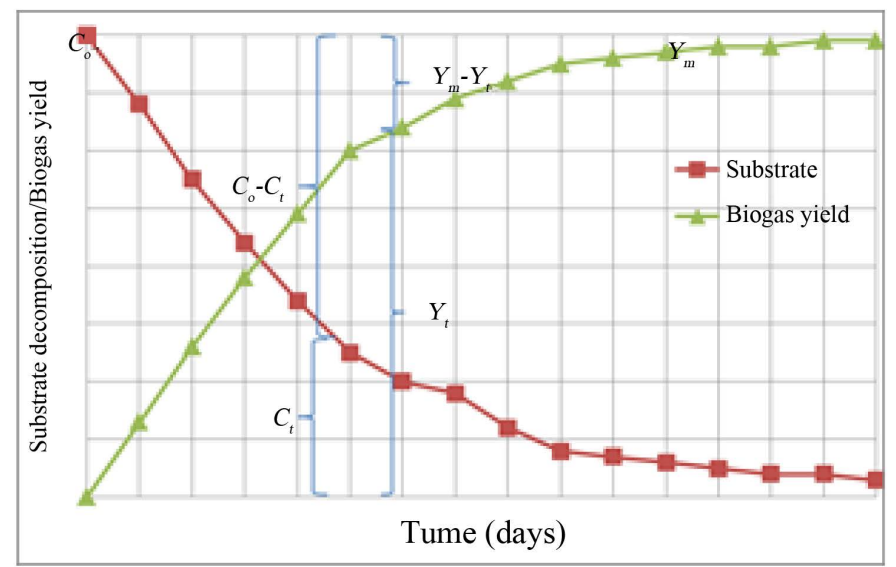

Figure 13. Pattern of transformation of volatile solids into biogas.

$$
\frac{y_{m}}{y_{m}-y_{t}}=\frac{C_{o}}{C_{t}}
$$

Equation (1) is linked to the first order rate degradation of the volatile solids in which $C_{o}$ is the initial volatile solids while $C_{t}$ is the volatile solids concentration at time $(t)$ given by Equation (2). 


$$
\ln \left(\frac{C_{t}}{C_{o}}\right)=-k t
$$

Replacing $\frac{C_{o}}{C_{t}}$ in Equation (2) with $\frac{y_{m}}{y_{m}-y_{t}}$ leads to Equation (3):

$$
\left(\frac{y_{m}-y_{t}}{y_{m}}\right)=\mathrm{e}^{-k t}
$$

Rearranging Equation (3) result into Equation (4)

$$
y_{m}\left(1-\mathrm{e}^{-k t}\right)=y_{t}
$$

where:

$y_{t}=$ volume of biogas produced per unit mass of volatile solids at any time $(t)$ during biodegradation.

$y_{m}=$ maximum yield volume of biogas per unit mass of volatile solids converted.

The rate constant associated with the degradation of the biodegradable fractions is represented by $k(1 /$ days), while the period of digestion is represented by $t$ (in days).

The application of Equation (4) in assessing substrate biodegradability and the rate constant was accomplished by linearising Equation (4) as shown below. By differentiating Equation (4), Equation (5) is obtained,

$$
\frac{\mathrm{d} y_{t}}{\mathrm{~d} t}=y_{m} k \mathrm{e}^{-k t}
$$

Taking natural logarithm on both sides of the Equation, the Equation (6) is obtained,

$$
\ln \left(\frac{\mathrm{d} y_{t}}{\mathrm{~d} t}\right)=\left(\ln y_{m}+\ln k\right)-k t
$$

which can be reduced to the form shown in Equation (7),

$$
\frac{1}{t} \ln \left(\frac{\mathrm{d} y_{t}}{\mathrm{~d} t}\right)=\frac{1}{t}\left(\ln y_{m}+\ln k\right)-k
$$

Equation (7) is analogous to the straight line equation $y=m x+c$, in which $\left(\ln y_{m}+\ln k\right)$ represents the slope while, $(-k)$ represents the intercept of the plot of $\frac{1}{t} \ln \left(\frac{\mathrm{d} y_{t}}{\mathrm{~d} t}\right)$ against the inverse of the retention time. The term $\left(\ln y_{m}+\ln k\right)$ which is slope is a measure of the availability of readily and moderately degradable fractions of the substrate. Yusuf et al. (2011) [24] reported that, because of the limited time range of most biodegradability test, only the readily and moderately degradable fractions were consumed while the poorly or recalcitrant fractions were hardly affected. Thus, this term can be used to select substrate with the potential for high biogas production under short retention time. This term was referred to as the short term anaerobic biodegradability index (STABI). Higher values of STABI depict substrate with the potential to produce high quantity of biogas under short retention periods while lower values are indicative of substrate with the potential to produce low quantity of biogas under such condition from a given substrate volatile solids.

The term $(k)$ is a measure of the rate of removal of the biodegradable fractions in the feed materials (or substrate) as the biogas yield increases with time. Based on Equations (5) and (6) this rate constant is an indication of the first order kinetics for biodegradation of sisal waste. The first order kinetic constant is described by Eastman and Ferguson (1981) [25] as purely an empirical function that reflects the cumulative effects of many factors such as $\mathrm{pH}$, temperature, quantity and quality of substrate, rate of removal of the biodegradable fractions, rate of inhibition by other components of the substrate such as lignin or by-product of the reaction process such as fatty acids, etc.

As the value of $(k)$ becomes larger, the faster the rate of removal of the biodegradable fraction becomes. While as the value of $(k)$ becomes smaller, the slower the rate of removal of the biodegradable fraction becomes. Thus, Equation (7) can be used to measure the mesophilic temperature short term biodegradability and also identify anaerobic processes that are progressive or stressed [24]. 
The application of this modified first order model in assessing the short term biodegradability and removal rate of the biodegradable fractions was carried out for the substrates in LSD. The Equation revealed that digester with reduced size SDR operated at $40^{\circ} \mathrm{C}$ had the highest short term biodegradability. The plot of $\mathrm{G}$ versus $1 / \mathrm{t}$ revealed that the model equation could suitably assess the kinetics of sisal waste biodegradation in the temperature range from $25^{\circ} \mathrm{C}$ to $40^{\circ} \mathrm{C}$ because the lines were almost linear with linearity factor close to one $\left(R^{2} \cong 1\right)$ as shown in Figure 12 and Figure 13 .

From Figure 14 and Figure 15, the short term biodegradability of the substrate in reduced size LSD operated at atmospheric temperature for the period under study was observed to be 8.5843 while the intercept, depicting the removal rate of biodegradable fractions was estimated to be 0.1600 . The model was able to fit the data set with a goodness of fit $\left(R^{2}\right)$ of 0.9856 . Similarly, raw size LSD operated at atmospheric conditions, reduced size and raw size LSD operated at $40^{\circ} \mathrm{C}$ had short term biodegradability of 8.5136, 11.113 and 10.059 with a removal rate constant of $0.1732,0.5328$ and 0.475 and a goodness of fit of $0.9888,0.9935$ and 0.9969 as shown in Figure 14 and Figure 15.

In essence, substrate in reduced size LSD operated at $40^{\circ} \mathrm{C}$, with short term biodegradability of 11.113 , had the highest potential to produce more quantity of biogas for a given substrate volatile solid, followed by substrate in raw size LSD operated at $40^{\circ} \mathrm{C}$, raw size LSD operated at ambient temperature and lastly by substrate in reduced size LSD operated at atmospheric temperature.

Similarly, the modified first order model revealed that substrate in reduced size LSD operated at $40^{\circ} \mathrm{C}$ with a rate constant (k) of 0.5328 had the highest removal rate of biodegradable fraction. This means the highest rate of biogas production compared to other three cases shown in Table 2. The raw size LSD digested at atmospheric

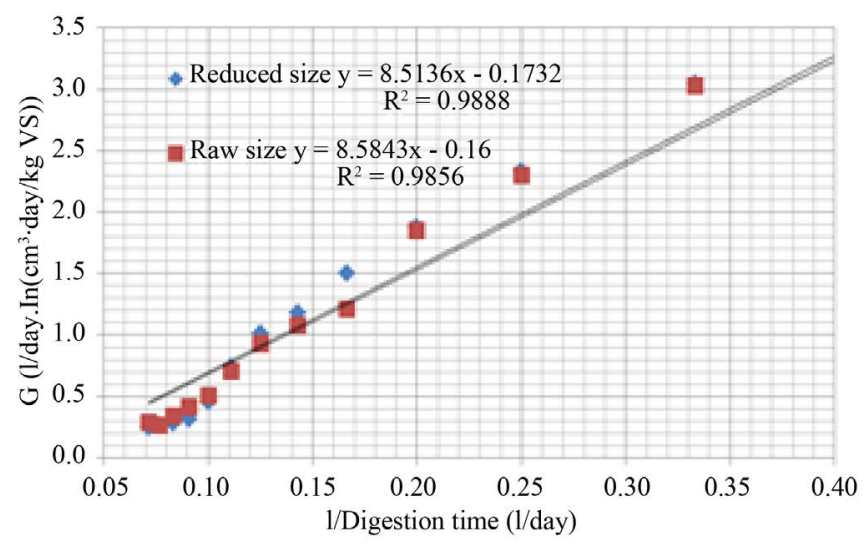

Figure 14. Plot of short term anaerobic biodegradability index versus reciprocal of digestion time of LSD operated at atmospheric condition.

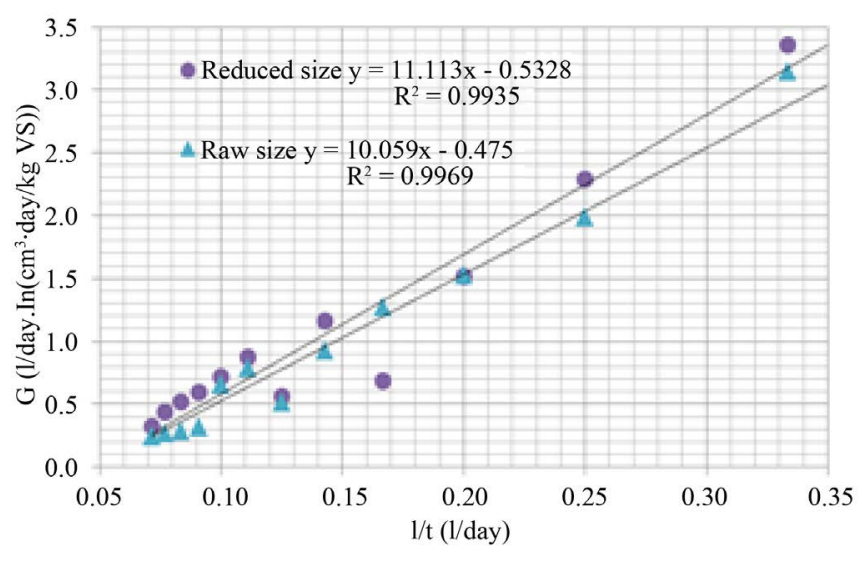

Figure 15. Plot of short term anaerobic biodegradability index versus reciprocal of digestion time of LSD operated at $40^{\circ} \mathrm{C}$. 
Table 2. Short term anaerobic biodegradability index (STABI) and rate constant (k) for different cases.

\begin{tabular}{ccccc}
\hline Cases & Temperature $\left({ }^{\circ} \mathbf{C}\right)$ & Size & STABI & $\mathbf{K}$ \\
\hline $\mathbf{1}$ & Atmospheric & Raw & 8.584 & 0.160 \\
$\mathbf{2}$ & Atmospheric & Reduced & 8.514 & 0.173 \\
$\mathbf{3}$ & 40 & Raw & 10.059 & 0.475 \\
$\mathbf{4}$ & 40 & Reduced & 11.113 & 0.533 \\
\hline
\end{tabular}

conditions had the lowest rate constant $(\mathrm{k})$ of 0.160 . That means the lowest biodegradable fraction of the total solids within equal digestion time with other cases. From this observation, rate constant (k) is directly proportional with increase in temperature and inversely proportional with increase in particle size of the SDR.

These results are supported with the studies carried out by Gollakota and Meher [26]. These authors demonstrated that both rate and yield were higher at $37^{\circ} \mathrm{C}$ than at $30^{\circ} \mathrm{C}$ when castor cake was used as substrate. Also pre-treatment such as grinding could significantly reduce the volume of the digester required without decreasing biogas production.

\section{Conclusions}

Sisal wastes have high potential to produce biogas when mechanically pre-treated by particle size reduction and digested in $\mathrm{AD}$ operated at temperature of $40^{\circ} \mathrm{C}$ compared to the one operated at lower atmospheric temperature. In this study LSD with SDR reduced in sizes operated at $40^{\circ} \mathrm{C}$ show that $0.5 \mathrm{~m}^{3}$ biogas can be obtained from 1 $\mathrm{kg}$ VS of sisal wastes. While LSD operated at room temperature without size reduction of SDR produce only 0.2 $\mathrm{m}^{3}$ biogas from $1 \mathrm{~kg}$ sisal wastes VS.

Kinetics of the SDR was enhanced to the significant values when size was reduced such that $90 \%$ of the particles passed through $2 \mathrm{~mm}$ sieve and operating temperature to be $40^{\circ} \mathrm{C}$ compared to kinetics of raw SDR where by only $46 \%$ of the particles can pass through $2 \mathrm{~mm}$ sieve and digested at atmospheric temperature $\left(28^{\circ} \mathrm{C}-\right.$ $32^{\circ} \mathrm{C}$ ). But temperature has large effect compared to size reduction.

Frequently failure of the motor at Hale biogas plant was caused by sisal fibres remaining in the SDR to accumulate the motor and resist its motion. This can be avoided by pre-treating the waste by either removing all fibres before feeding SDR to the biogas plant or size reduction of SDR to the extent that all long fibres will be shortened to the size which will not cause negative effect to the plant.

Pre-treatment of the SDR before feeding to the biogas plant is very important to be taken into consideration in the designing stage of the plant. Screening and size reduction units must be installed if sisal fibres are produced by corona to insure safety of the motor and pumps and also to enhance kinetics of SDR.

\section{Acknowledgements}

The success of this study has been made possible with financial assistance from University of Dodoma through Higher Education Student Loan Board (HESLB), University of Dar es Salaam through NOMA program. Both Universities are based in Tanzania and Katani limited for allowing their facilities and materials to be used for the study.

\section{References}

[1] Kowalczyk, A., Schwede, S., Gerber, M. and Span, R. (2011) Scale up of Laboratory Scale to Industrial Scale Biogas Plants. World Renewable Energy Congress, Bioenergy Technology, Linköping, 8-13 May 2011, Article No.: 007. http://dx.doi.org/10.3384/ecp1105748

[2] Chynoweth, D.P., Owens, J.M. and Legrand, R. (2001) Renewable Methane from Anaerobic Digestion of Biomass. Renewable Energy, 22, 1-8. http://dx.doi.org/10.1016/S0960-1481(00)00019-7

[3] Salum, A. and Hodes, G. (2009) Leveraging CDM to Scale-Up Sustainable Biogas Production from Sisal Waste. UNEP Risoe Centre (URC), National Laboratory for Sustainable Energy, Technical University of Denmark, Roskilde.

[4] Mshandete, A.B., Björnsson, L., Kivaisi, A.K., Rubindamayugi, M.S.T. and Mattiasson, B. (2005) Performance of a Sisal Fibre Fixed-Bed Anaerobic Digester for Biogas Production from Sisal Pulp Waste. Tanzania Journal of Science, 31, 41-51. 
[5] Ayalon, O., Avnimelech, Y. and Shechter, M. (2001) Solid Waste Treatment as a High-Priority and Low Cost Alternative for Greenhouse Gas Mitigation. Environmental Management, 27, 697-704. http://dx.doi.org/10.1007/s002670010180

[6] Deubleim, D. and Steinhauser, A. (2008) Biogas from Waste and Renewable Resources: An Introduction. Wiley-VCH Verlag GmbH and Co KGaA, Weinheim.

[7] Yadvika, S., Sreekrishnan, T., Kohli, S. and Rana, V. (2004) Enhancement of Biogas Production from Solid Substrates Using Different Techniques-A Review. Bioresource Technology, 95, 1-10. http://dx.doi.org/10.1016/j.biortech.2004.02.010

[8] Wanasolo, W., Manyele, S.V. and Makunza, J. (2013) A Kinetic Study of Anaerobic Biodegradation of Food and Fruit Residues during Bigas Generation Using Initial Rate Method. Engineering, 5, 577-586. http://dx.doi.org/10.4236/eng.2013.57070

[9] Yang, Y., Tsukahara, K., Yagishita, T. and Sawayama, S. (2004) Performance of a Fixed Bed Reactor Packed with Carbon Felt during Anaerobic of Cellulose. Bioresource Technology, 94, 197-201. http://dx.doi.org/10.1016/j.biortech.2003.11.025

[10] Dichtl, N., Müller, J., Braunschweig, E.E., Günthert F.W. and Osswald, M.O. (1997) Waste Sludge Disintegration: A Recent Overview. Korrespondenz Abwasser, 44, 1726-1739 (in German).

[11] Li, Y.Y. and Noike, T. (1992) Upgrading of Anaerobic Digestion of Waste Activated Sludge by Thermal Pre-Treatment. Water Science and Technology, 26, 857-866.

[12] Tanaka, S., Kobayashi, T., Kamiyama, K. and Bildan, M.L.S. (1997) Effects of Thermochemical Pre-Treatment on the Anaerobic Digestion of Waste Activated Sludge. Water Science and Technology, 35, 209-215. http://dx.doi.org/10.1016/S0273-1223(97)00169-8

[13] Weemaes, M. and Verstraete, W. (1998) Evaluation of Current Wet Sludge Disintegration Techniques. Journal of Chemical Technology and Biotechnology, 73, 83-92. http://dx.doi.org/10.1002/(SICI)1097-4660(1998100)73:2<83::AID-JCTB932>3.0.CO;2-2

[14] Sharma, S.K., Mishra, I., Sharma, M. and Saini, J. (1988) Effect of Particle Size on Biogas Generation from Biomass Residues. Biomass, 17, 251-263. http://dx.doi.org/10.1016/0144-4565(88)90107-2

[15] Moorhead, K. and Nordstedt, R. (1993) Batch Anaerobic Digestion of Water Hyacinth: Effects of Particle Size, Plant Nitrogen Content, and Inoculum Volume. Bioresource Technology, 44, 71-76. http://dx.doi.org/10.1016/0960-8524(93)90211-S

[16] Mshandete, A., Kivaisi, A., Rubingamayugi, M. and Mattiasson, B. (2004) Anaerobic Batch Co-Digestion of Sisal Pulp and Fish Wastes. Bioresource Technology, 95, 19-24. http://dx.doi.org/10.1016/j.biortech.2004.01.011

[17] Sinnott, R.K. (1999) Coulson and Richardson's Chemical Engineering Volume 6, Chemical Engineering Design. Butterworth-Heineman, Oxford.

[18] APHA (1999) Standard Method for the Examination of Water and Wastewater. American Public Health Association, American Water Works Association, Water Environment Federation, Washington DC.

[19] Buchauer, K. (1998) A Comparison of Two Simple Titration Procedures to Determine Volatile Fatty Acids in Influents to Waste-Water and Sludge Treatment Processes. Water South Africa, 24, 49-56.

[20] Kivaisi, A.K. and Eliapenda, S. (1994) Pre-Treatment of Bagasse and Coconut Fibres for Enhanced Anaerobic Degradation by Rumen Microorganisms. Renewable Energy, 2, 791-795. http://dx.doi.org/10.1016/0960-1481(94)90089-2

[21] Hills, D.J. and Nakamo, K. (1984) Effect of Particle Size on Anaerobic Digestion of Tomato Solid Wastes. Agricultural Wastes, 10, 285-295. http://dx.doi.org/10.1016/0141-4607(84)90004-0

[22] Angelidaki, I. and Ahring, B.K. (2000) Methods for Increasing the Biogas Potential from the Recalcitrant Organic Matter Contained in Manure. Waste Science Technology, 3, 189-194.

[23] Linke, B. (2006) Kinetic Study of Thermophilic Anaerobic Digestion of Solid Wastes from Potato Processing. Biomass and Bioenergy, 30, 892-896. http://dx.doi.org/10.1016/j.biombioe.2006.02.001

[24] Yusuf, M.O., Debora, A. and Ogheneruona, D.E. (2011) Ambient Temperature Kinetic Assessment of Biogas Production from Co-Digestion of Horse and Cow-Dung. Resource Agricultural Engineering, 57, 97-104.

[25] Eastman, J.A. and Ferguson, J.F. (1981) Solubilization of Particulate Organics Carbon during the Acid Phase of Anaerobic Digestion. Journal Water Pollution Control Federation, 53, 352-366.

[26] Gollakota, K.G. and Meher, K.K. (1988) Effect of Particle Size, Temperature, Loading Rate and Stirring on Biogas Production from Castor Cake. Biological Waste, 24, 243-249. 